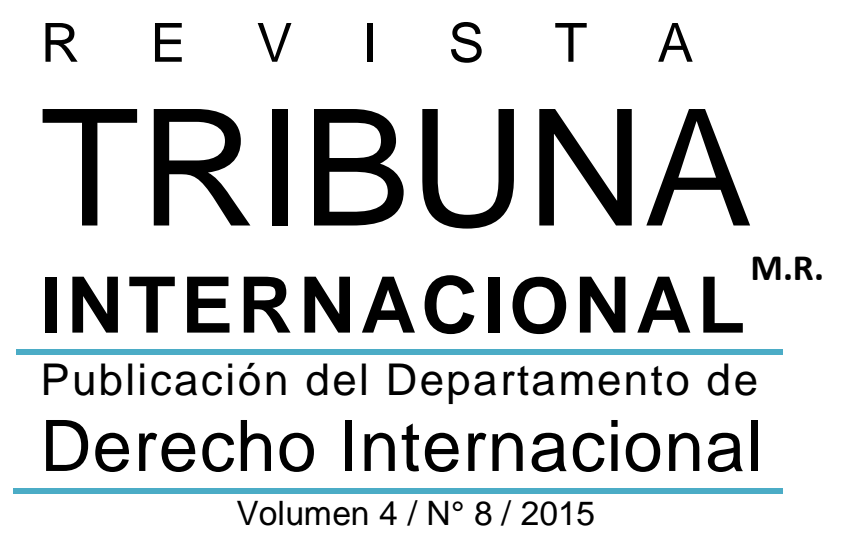

FACULTAD DE DERECHO 


\section{Rector de la Universidad de Chile}

Ennio Vivaldi Véjar

Av. Alameda Libertador Bernardo O'Higgins 1058, Santiago

\section{Representante legal}

Davor Harasic Yaksic

Decano de la Facultad de Derecho

Universidad de Chile

\section{Director Departamento Derecho Internacional}

Edmundo Vargas Carreño

\section{Director (S) Revista Tribuna Internacional}

Mario Arnello Romo

\section{Editor General Revista Tribuna Internacional}

Luis Valentín Ferrada Walker

\section{Comité Editorial}

Íñigo Álvarez Gálvez (Universidad de Chile, Chile)

Gonzalo Aguilar (Universidad de Talca, Chile)

José Carlos Fernández Rosas (Universidad

Complutense de Madrid, España)

Claudio Grossman (American University, EE.UU.)

Mattias Kumm (New York University, EE.UU.)

Hugo Llanos (Universidad Central, Chile)

Cecilia Medina (Universidad Diego Portales, Chile)

Elina Mereminskaya (Universidad de Chile, Chile)

Mónica Pinto (Universidad de Buenos Aires, Argentina)

\section{Fundador de la Revista Tribuna Internacional}

Mario Ramírez Necochea $†$

\section{Revista Tribuna Internacional M.R.}

Publicación del Departamento de Derecho Internacional de la Facultad de Derecho de la Universidad de Chile. Su objetivo es fomentar la reflexión, el debate, el análisis y la comunicación sobre el derecho internacional en forma pluralista y con rigor científico. Se publica cada semestre en los meses de junio y diciembre mediante convocatoria abierta a la publicación de artículos y monografías inéditos, comentarios de jurisprudencia, recensiones y comentarios de libros, en los campos de derecho internacional público y privado, derecho internacional de los derechos humanos y relaciones internacionales, tanto en castellano como inglés.

La Revista Tribuna Internacional fue creada por Decreto Exento No 8.466 de la Rectoría de la Universidad de Chile, de 22 de marzo del 2011

Volumen 4/ No 8 / 2015

www.tribunainternacional.uchile.cl ISSN 0719-482X (versión en línea)

Departamento de Derecho Internacional Facultad de Derecho Universidad de Chile Av. Santa María 076, $4^{\circ}$ piso Providencia, Santiago de Chile

\section{Diseño y producción:}

Facultad de Derecho

Universidad de Chile

Se autoriza la reproducción total o parcial del contenido de la publicación, siempre que se reconozca y cite el/ la/ los/ las autor/a/es/as y la publicación, no se realicen modificaciones a la obra y no se la utilice para fines comerciales. 


\title{
"La Punta del iceberg. La aspiración marítima boliviana y sus implicancias en la seguridad y defensa de Chile"
}

\author{
Pablo León, Cristián Faundes, Marjorie Gallardo (editores), 2015, Centro de Estudios \\ Estratégicos de la Academia de Guerra (Ejército de Chile), Santiago, 224 pp.
}

Por Sebastián Flores Díaz

El miércoles 9 de septiembre de 2015, en la Academia de Guerra del Ejército se presentó el libro La Punta del iceberg. La aspiración maritima boliviana y sus implicancias en la seguridad y defensa de Chile (disponible de forma gratuita en Internet') en conjunto con la revista Ensayos Militares (también disponible en Internet $\left.{ }^{3}\right)$ ). El trabajo fue presentado por el profesor José Rodríguez Elizondo, Director del Programa de Relaciones Internacionales de la Facultad de Derecho de la Universidad de Chile.

Esta obra es el fruto del trabajo de intelectuales civiles y militares. Los militares por formación profesional estudian y trabajan con la estrategia, por lo mismo, La punta de iceberg... propone un análisis estratégico de un tema de coyuntura, en el que es necesario tener valentía para expresar opiniones divergentes de la pauta oficial fijada por la diplomacia legalista chilena.

El libro se centra en una coyuntura demasiado larga. ¡Siete años a la defensiva en el Tribunal Internacional de las Naciones Unidas! Primero con Perú. Ahora con Bolivia. Siete años en que la política exterior está judicializada y controlada por los estudios jurídicos internacionales. Siete años sin que Chile haya levantado una estrategia que permita tomar la iniciativa en sus relaciones vecinales.

La importancia del tema es excepcional no sólo para el público interesado en los ámbitos de la defensa. Su trascendencia está en su aporte a la política exterior, tanto por lo que el libro no es, como por lo que el libro es. No es un libro "técnico militar". No se concentra en potenciales comparados. Tampoco en relaciones histórico militares o en efectivos y equipamientos. No se abordan las proyecciones del sector.

\footnotetext{
Abogado, Universidad de Chile. Profesor de Derecho Militar en la Escuela Militar del General Libertador Bernardo O'Higgins y profesor de Derecho Internacional Privado en UNIACC. En la actualidad realiza su tesis de Magíster en Derecho, porla Universidad de Chile. sfloresabogado@derecho.uchile.cl.

2 Centro de Estudios Estratégicos de la Academia de Guerra (Ejército de Chile). [en línea] <http://www.ceeag.cl/wp-content/uploads/2015/09/La-Punta-del-Iceberg-WEB.pdf> [consulta: 20.dic.2015].

3 Centro de Estudios Estratégicos de la Academia de Guerra (Ejército de Chile). [en línea]

<http://www.ceeag.cl/wp-content/uploads/2015/09/ENSAYOS-MILITARES-2-final-web.pdf> [consulta: 20.dic.2015].
} 
"La Punta del iceberg. La aspiración marítima boliviana y sus implicancias en la seguridad y defensa de Chile" Pablo León, Cristián Faundes, Marjorie Gallardo (editores)

Se trata de un libro que entrega una visión de Bolivia desde el pensamiento estratégico. Es decir, obliga a conocer al "otro". Esto comprende cuatro aspectos principales:

a) Concepto y posibilidades del nuevo Estado Plurinacional.

b) Sus componentes políticos, geopolíticos, étnico-sociales, económicos, internacionales, diplomáticos y, por cierto, militares.

c) Lo estratégicamente significativo para Chile y sus vecinos.

d) Calidad real del liderazgo del Presidente Evo Morales.

El libro permite responder preguntas decisivas para el presente y futuro de la relación chilenoboliviana. Especialmente acerca de la estatura estratégica de Bolivia en la actualidad y su proyección a mediano y largo plazo. O acerca de si la judicialización de la demanda marítima boliviana pueda ser una la solución a su aspiración. También aborda la interrogante de si un fallo adverso para Bolivia puede terminar con el hostigamiento hacia Chile.

La obra ilumina algunas coincidencias llamativas entre Chile y Bolivia. Por ejemplo, que ambos países soslayan el carácter trilateral real de la aspiración marítima boliviana. Por lo tanto, soslayan que Arica es el objetivo histórico y vigente de La Paz. También que el Perú es un tercero jurídicamente eventual. Así como que el Perú es un protagonista político permanente.

El libro entrega cinco grandes lecciones:

a) Para defender la soberanía territorial no basta con una "sólida posición jurídica".

b) La diplomacia no se reduce a la aplicación de la letra de los tratados internacionales.

c) Derivado de lo anterior, la negociación es la esencia de la diplomacia, y sin ella, no hay legítima disuasión creíble.

d) Los conflictos deben enfrentarse con el esquema de las 3 D: Derecho, Diplomacia y Defensa.

e) Este esquema necesita una estrategia integral y actualizada.

El libro apela a la existencia de una verdadera política de Estado para aplicar estas lecciones. Una política sincera con nuestro pasado en donde el tema boliviano se ha conversado de espaldas a la opinión pública, sin saber cuánto se comprometió con La Paz. Una política integral que contenga imaginación prospectiva para producir acción en la inerte diplomacia chilena y creatividad para dar soluciones a los conflictos vecinales. Esto se ve más claro desde el ámbito militar que es el hábitat originario de la estrategia. Ámbito donde procesar los errores es una necesidad profesional (en donde se define la vida o la muerte). Basta recordar al general 
Revista Tribuna Internacional

Volumen $4 \cdot \mathrm{N}^{\text {o }} 8 \cdot 2015 \cdot$ pp. $293-295$

ISSN 0719-482X (versión en línea)

De Gaulle, quien señalaba que los ejércitos construyen sus doctrinas reparando los errores cometidos en el último conflicto.

Otra de las lecciones que nos entrega el libro es la necesidad de enfrentar los errores cometidos en las relaciones vecinales, así como la importancia de reconocer el método que se esconde en la agresividad de Evo Morales.

Harold Nicolson, tratadista británico, indicaba que hay quienes, ante el riesgo de dar un mal paso, optan por no dar paso alguno. El libro invita superar esto. Llama a salir de la espera reactiva de diplomacia chilena haciendo hincapié en superar la aversión al riesgo. 